\title{
Analysis the Risk Elements of Smes in the Region of Gjirokastra
}

\author{
Dr. Lorenc Koçiu
}

"Eqrem Çabej” University, Gjirokaster; Email: kociulorenc@yahoo.com

\section{Dr. Robert Çelo}

“Eqrem Çabej” University, Gjirokaster; Email: bertcela1@hotmail.com

\section{Dr. Romeo Mano}

“Eqrem Çabej” University, Gjirokaster; Email: manoromeo2002@yahoo.com

\section{Doi:10.5901/ajis.2015.v4n3s1p627}

\begin{abstract}
SMEs are one of the biggest engines of the European economy, and also the Albanian economy. SMEs create opportunities for increased employment and sustainable growth. In Europe, SMEs, businesses that employ less than 250 employees and with a turnover of less than $€ 50$ million, up about $99 \%$ of enterprises in Europe (23 million SMEs), and have in their midst about 75 million employees. The group of businesses included within the SME group faces problems with completely unique nature of doing business, because of the difficulties in providing sufficient resources as financial ones as well as human ones. Financial capital is very limited for this group of businesses compared to large companies, which are likely many times greater for finding significant financial resources, compared with the few opportunities to SMEs. Likewise, in connection with human capital of SME opportunities are limited in attracting a skilled human capital compared with possibilities of large companies. For the successful realization of this paper is using descriptive method and interpretation of charts, based on primary data obtained setup by questionnaires addressed to SMEs in Gjirokastra. At the end of the paper showed that the factors that affect the identification of risk analysis should be grouped according to their importance and the source, due to the diversity and different sources from which they arise.
\end{abstract}

Keywords: risk, SMEs, Gjirokastra, risk identification, financial capital, human capital.

\section{Introduction}

SMEs are one business group that faces most frequent changes that occur in the market in which they operate, and therefore they face often with bankruptcies, failures, financing difficulties, lack of liquidity, the difficulties of lending, staff unskilled and many other difficulties. According to data and scientific literature concerning SMEs, it was determined that the number of births and closures of SMEs is many times greater than that of big business. This despite the fact that there are legal changes permitting and control of the activities of SMEs compared with those of big business.

The market in which they operate SMEs is a market with a very tough competition, problems and difficulties in the introduction of new products, their distribution, finding segments of the new market of existing SMEs and the New, which tend newly entering the market. This for many reasons, among which we can mention the size of these types of businesses, limited financial possibilities and constraints in attracting the best qualified personnel compared with big business.

Big business has more opportunities in finding financial resources, whether internal resources or external, realizes a turnover many times higher than SMEs, has better opportunities for recruitment and selection of human capital, which in most cases want to be employed in these businesses than at SMEs. Also there is the possibility for better remuneration of staff at large businesses compared with SMEs. Type of assets is diversified to big business than SMEs.

The risk faced by SMEs in their daily decision-making, implementation in practice, the absorption of personnel, as well as many other issues is very different from the risk faced by big business. It is therefore very important that SMEs assess factors influencing the identification of risk with which they are confronted.

In Albania the SMEs have a significant role in the economy. They are important as large in scope of their territory of the Republic of Albania, but also for the large number of them compared to large businesses and those operating in 
the field of agriculture. According to the data of recent years their number is 101.917 , while the total number of businesses is 102.767 , so they occupy around $99 \%$ of the total number of businesses in Albania ${ }^{1}$.

\section{Review of the Literature}

In Europe the SMEs regarded as businesses within the group of businesses that employ less than 250 employees and with a turnover of less than $€ 50$ million, which represent about $99 \%$ of enterprises in Europe (23 million SMEs) as and within their 75 million employees.

While the definition of business in Albania as part of SMEs is regulated by Law no. 8957, dated 17.10.2002 "On Small and Medium Enterprises", as amended, in which the definition of what is called micro-enterprises, small enterprises and medium-sized enterprise. Microenterprise called those enterprises, which employ up to nine employees and their annual economic turnover not exceeding 10 million Lek ${ }^{2}$. Small enterprises called those enterprises which employ 10 to 49 employees and have a turnover up to 50 million Lek. Medium Enterprises refers to those enterprises which employ 50 to 249 employees, has a turnover or annual balance sheet total up to 250 million.

Diversified is also the concept that the risk that SMEs face, according to many researchers in this field. According Tchankova (2002) risk is associated with the uncertainty, where the achievement of objectives is dependent on the occurrence or non-occurrence of events. Uncertainty, and thus the risk prevails in all sphere of life, in business, the economy and the environment, where unstable market relations, increasing insecurity in the environment in which organizations operate.

According to Spira \& Page (2003), risk is integral to all business activities and it affects all management levels. Business leaders face risks that are caused by external forces beyond the capacity of business to control these forces. These external forces are combined with a large number of internal forces, such as the change in the organizational structure, and should be managed (Bowling et al, 2003).

According to Smit (2012) uncertainty arises in situations in which decision makers have the knowledge, information and incomplete understanding of the activities and their possible consequences. The main source of the birth of uncertainty is the lack of information about the upcoming event.

According to Kimball (2000) the risk is injected into economic activity through various outflows of economic resources, which are carried out without knowing if it will be followed by positive incoming flows.

However, to control the risk or its effective management need to determine the nature, the probability of occurrence and impact. Risk management process provides an effective and structured approach to identify, assess and control. Although effective control of risk exposure affects the reduction of potential losses, he cannot eliminate undesirable events from occurring. An environmental assessment of the risk structure increases the ability to address risk and provides financial protection to protect the organization from the impact of negative events (Andersen \& Terp, 2006).

\section{The Objectives and Hypotheses}

The main objective of this paper is to evaluate the factors that affect the identification of risk faced by SMEs in the region of Gjirokastra. In order to achieve the main objective research questions were raised:

$>$ SMEs in the region of Gjirokastra recognize the risks they face?

$>$ Are capable SMEs in the region of Gjirokastra identifying factors influencing the emergence of risk?

\section{Methodology}

For the successful realization of this paper we rely on statistical data study of two types: primary and secondary. Primary data were obtained directly from subjects through interviews with the help of a questionnaire, which was developed with the purpose of data collection mainly qualitative, but also quantitative, which have direct links to qualitative data. Secondary data were provided using contemporary literature, which supports paper theoretically, on official data from the Albanian institutions, and from other appropriate sources of study.

On the provision of qualitative and quantitative data is compiled a structured questionnaire. A structured

\footnotetext{
1 "Shqipëria në shifra 2012", INSTAT - Tiranë 2013

${ }^{2}$ Lek is called the Albanian money
} 
questionnaire options different presents for each question, and the interviewer should simply select the appropriate response (Babbie, 1990). The questionnaire is an instrument to collect data from the population to be studied. The objective of the use of the questionnaire is to help the applicant to reach conclusions (Jankowicz 2000).

A questionnaire is considered as a technique which is used to collect data which express individual perceptions of each subject interviewed in the sense that every individual is asked to answer questions in a predetermined way.

The data provided is created database, through which are built graphics different interpretation which explains how SMEs in the region of Gjirokastra evaluate factors its potential that affect the risks that they face and efforts them to avoid the risk of different types.

\section{Analysis of Data}

For the successful implementation of this work was laid on the ground about 200 questionnaires, of which 175 were regular and the rest of the questionnaires were not completed correctly by the interviewees.

The questionnaire was divided into three sections, with the first section serving for the provision of personal information related to the interviewee as age, education, gender, etc. The second section serving to ensure that generic information about the entity as the type of activity, number of employees, turnover and business age. While, in the third section was made possible providing data that explain how SMEs understand the risk, take steps to identify him and measures to protect him.

From demographic analysis made by the first section and the second resulted in the classification of the activity $41.1 \%$ principal activity is trade, $21.8 \%$ are manufacturing businesses, $30.3 \%$ are businesses that provide services and $6.8 \%$ of the businesses are field construction.

By number of employees showed that $78.3 \%$ of businesses employing up to 9 employees, $21.7 \%$ are employed from 10 to 49 employees, while in the category of 50 to 249 employees, there were no business study.

According to the classification of turnover showed that $64 \%$ of businesses have a turnover of up to 10 million, $30.3 \%$ have a turnover of 10 million to 50 million and only $5.7 \%$ have a turnover of 50 million to 250 million.

According to the classification of the age of the business showed that $11.4 \%$ of SMEs interviewed are relatively young age to 5 years, $46.3 \%$ of them included in the age group 5 to 10 years, $16 \%$ of them belong to the age group 10 to 15 years and about $26.3 \%$ of them belong to the age group from 15 to 24 years, table 1.

Table 1. Demographic analysis of SMEs trade

\begin{tabular}{||c|c|c|c||}
\hline \multirow{4}{*}{ Activity } & Trade & 72 & $41.1 \%$ \\
\cline { 2 - 4 } & Manufacturing & 38 & $21.8 \%$ \\
\cline { 2 - 4 } & Service & 53 & $30.3 \%$ \\
\cline { 2 - 4 } & Construction & 12 & $6.8 \%$ \\
\hline \hline \multirow{3}{*}{ Number of employees } & $1-9$ & 137 & $78.3 \%$ \\
\cline { 2 - 4 } & $10-49$ & 38 & $21.7 \%$ \\
\cline { 2 - 4 } & $50-249$ & 0 & $0 \%$ \\
\hline \hline \multirow{3}{*}{ Turnover (in Lek) } & $<10$ million & 112 & $64.0 \%$ \\
\cline { 2 - 4 } & $10-50$ million & 53 & $0.3 \%$ \\
\cline { 2 - 4 } & $50-250$ million & 10 & $5.7 \%$ \\
\hline \hline \multirow{3}{*}{ Age of business (years) } & $<5$ & 20 & $11.4 \%$ \\
\cline { 2 - 4 } & $5-10$ & 81 & $46.3 \%$ \\
\cline { 2 - 4 } & $10-15$ & 28 & $16.0 \%$ \\
\cline { 2 - 4 } & $15-24$ & 46 & $26.3 \%$ \\
\hline
\end{tabular}

Source: Author, 2015

SMEs in the region of Gjirokastra have appreciated as a significant factor that causes birth risk frequent changes in tax legislation. The question "How have frequent changes of the tax legislation affected in your business?" showed that the activity of $6 \%$ of SMEs surveyed is significantly affected by changes to the legislation, $50 \%$ of them stated that their constant activity has had an impact of legislation acceptable changes, $34 \%$ of them stated that their constant activity is 
little affected by changes in legislation and $10 \%$ have stated that legislative changes have had no impact at all on their activity, chart 1. So, in conclusion it can be said that SMEs in the region of Gjirokastra perceive that frequent legislative changes have a significant effect on their activity, being considered as a potential risk factor with which they face.

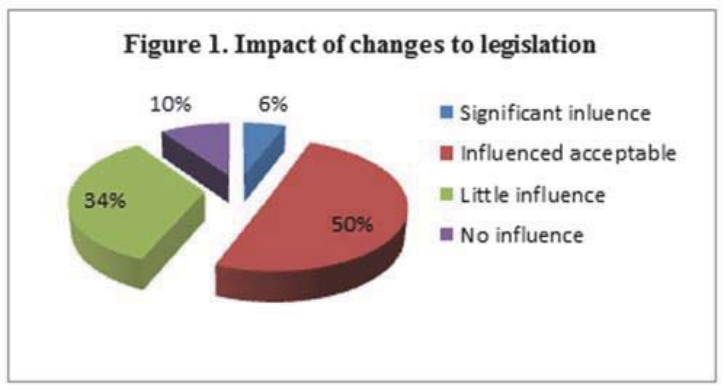

SMEs in the region of Gjirokastra perceive debt issuance as a potential risk factor, but often are forced to go to him. The question "Do you have used any bank loan for your activity?" showed that $55 \%$ of SMEs surveyed have used the bank loan, while $45 \%$ of them have not used it, figure 2 .

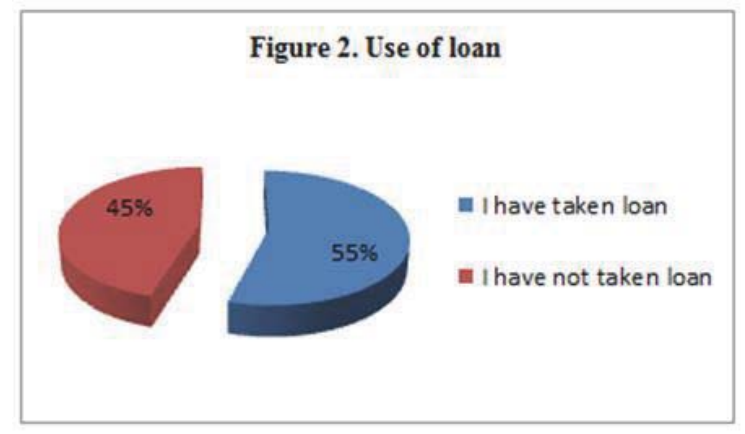

Another important factor to consider is the way in which SMEs finance their long-term assets. To highlight this factor arose the question "How did you finance your long-term assets (fixed assets)", The answer of which showed that 12\% of SMEs surveyed have financed with debt outside the banking system, $16 \%$ of them have funded with short-term bank loans, $30 \%$ of them financed with long-term bank loans, $29 \%$ of them financed by owner's equity and $13 \%$ have received as gift, figure 3 .

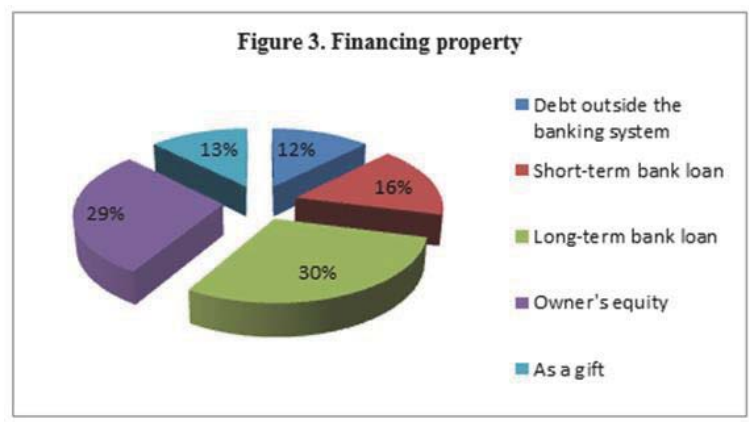

According Thomsett (2006) to be protected from the risk SMEs should remember two golden rules of the financing the long-term assets: the first rule, long-term assets should be covered by own equity - only in this case provided financial 
equilibrium. The second rule, long-term assets can be financed by fixed capital, which includes own equity and long-term debt. If the entity, at least, stands at the second rule then ensure a balance financial and a low level of risk of disability margin. Otherwise, the entity does not comply with the order or first or second, it is facing possible bankruptcy risk.

Another factor that has led many SMEs in financial difficulty was the increase of the amounts uncollected (Accounts receivable) by their customers. SMEs need to be cautious in their collection policies, trying to reduce or maintain control of these amounts. For this reason in the questionnaire is raised the question "Is the increase from year to year the amount of uncollected money from customers?". From the answers given showed that $65 \%$ of SMEs surveyed said they did not have growing amounts uncollected by clients, while $35 \%$ of them stated that they had increased year on year amounts uncollected add annually "bad debt", figure 4.

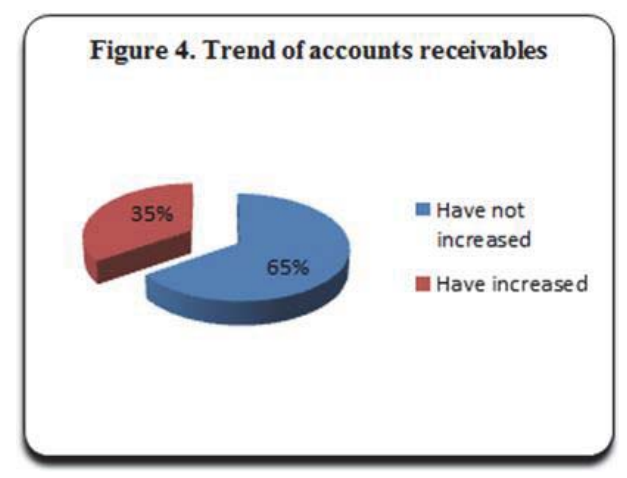

\section{Conclusions and Recommendations}

At the conclusion of this study showed that SMEs in the region of Gjirokastra pay great attention to the risks they face and make efforts to identify the factors that cause these risks. The activity of SMEs affected by the change enormously fiscal legislation, causing SMEs to consider these changes as a potential factor for the emergence of risk. Also the use of debt is regarded as a risk factor, especially in cases where the cost of using debt is not covered by the return on the investment made to put in financial difficulty at the time of payment business debt. SMEs perceive a risk factor is the way the assets are financed long term, because it is very dangerous for the activity of SMEs to finance these assets with short-term resources. Such a situation would lead to SMEs definitely their bankruptcy. Finally, SMEs pay a great attention to the amount of accounts receivable, trying to maintain its low levels and revenue from previous amounts quickly in time.

\section{References}

Andersen, Karsten, and Anette Terp. "Risk Management." In Perspectives on Strategic Risk Management, by Torben Juul Andersen, 2747. Denmark: Copenhagen Business School Press, 2006.

Babbie, Earl R. Survey Research Methods, 2nd edition. USA: Wadsworth Cengage Learning, 1990.

Bowling, D, F Julien, and L Rieger. "Taking the Enterprise Risk - Management Journey." Bank Accounting \& Finance, 2003: 16(2): 1622.

Jankowicz, A. D. Business Research Projects (3rd edition). London: Thomson Learning, 2000.

Kimball, Ralph C. "Failures in Risk Management." New England Economic Review, January/February, 2000: 1-12.

Smit, Yolande. "A Structured Approach to Risk Management for South African SMEs." Cape Town: Cape Peninsula University of Technology, March 2012.

Spira, Laura F, and Michael Page. "Risk management: The reinvention of internal control and the changing role of internal audit." Accounting, Auditing \& Accountability Journal, Vol 16, No 4, 2003: 640-661.

Tchankova, Lubka. "Risk identification - Basic stage in risk management." Environmental Management and Health, Vol 13, 2002: 290297.

Thomsett, Michael C. Getting Stared in Fundamental Analysis. USA: John Wiley \& Sons,Inc., 2006. 